\title{
PHYSIOLOGICAL STUDY OF THE STRATIFICATION EFFECT ON THE DYNAMIC CHANGES IN ENDOGENOUS ABSCISIC ACID IN BITTER ALMOND SEEDS (Prunus amygdalus L.) AND ITS RELATION TO SEEDS GERMINATION.
}

\author{
Nabil M. Ameen Al-Imam \\ Dept. of Horticulture, College \\ of Agric. and Forestry, \\ University of Mosul, Iraq
}

\author{
Mostafa M. Qrunfleh \\ Dept. of Plant Production, Faculty \\ of Agric. University \\ of Jordan, Amman, Jordan
}

\begin{abstract}
Endogenous concentrations of free and bound abscisic acid (ABA) in bitter almond seeds Badam variety (local variety) from Sulaimania orchards Prunus amygdalus L. were determined by TLC and HPLC during various periods of cold stratification (0,15,30,45, and 60 days) and the germination was investigated at the Plant Hormones Laboratory in the Department of Plant Production, Faculty of Agriculture, University of Jordan, Amman, Jordan, during the period 2004 to 2005 . The results indicated that cold stratification (at $5{ }^{\circ} \mathrm{C}$ using perforated polyethylene bags filled with moistened perlite) significantly reduced abscisic acid (ABA) contents of the seeds and their endocarps. A sharp significantly decline in ABA was observed during the first 15 days, especially in 45 days, after that the decline was completely decreased. The reduction in the level of $\mathrm{ABA}$ during stratification was associated with significantly increased germination percentage especially for 45 days $(85.133 \%)$.
\end{abstract}

\section{INTRODUCTION}

Native rootstocks are adapted to local environments and tolerate prevailing harsh conditions better than any other introduced unadapted rootstocks (Khalil, 1997). The bitter almond (Prunus amygdalus L.) of Rosaceae family is one of the most important rootstocks of almond cultivars especially under rain fed (unirrigated) condition in the north of Iraq (Yousif, 1987).

Almond seedlings are quite satisfactory in deep and well-drained soils, their deep rooting tendency in an advantage in orchards grown under unirrigated or where drought conditions occur, almond seedlings are tolerant of high-lime soils and, of all of the rootstocks available for almond, are the least affected by excess boron salts (Hartmann and Kester, 1975).Seeds displaying intermediate physiological dormancy usually require chilling stratification to release seeds from dormancy (Hartman et al., 2002) and to reduce levels of growth inhibitor, in seeds of peach such as ABA (Bonamy and Dennis, 1977). Stratification is a method of handling dormant seeds in which imbided seeds are subjected to a period of chilling to alleviate dormancy conditions in the embryo, this is the most common treatments for seeds with endogenous physiological dormancy (Hartmann et al., 2002). Abscisic acid (ABA) is found in most monocots, dicots, conifers and ferns at level of 0.01 to 1 part per million (ppm) of fresh 
tissue and the effect of ABA suggest some action at the plasma membrane and inhibition of RNA and enforcement of seeds dormancy (Ponicelot, 2004). Abscisic acid, is a naturally occurring material, and is one of a classes of growth inhibitors that play an important role in plant activities (Addicott, 1992 ; George, 1993). ABA is involved primarily in regulating seed germination, inducing storage, protein synthesis and modulating water stress of seeds and also in a potent germination inhibitor (Hopkins and Hüner,2004).Seeds stratification and changes in hormone levels during chilling stratification have been studied extensively in pear embryo (Tao and Khan, 1976), peach (Daize and Martin, 1972), and hawthorn (Qrunfleh, 1991). However, in Iraq there are a lot of information about the bitter almond specially on changes in ABA levels during chilling stratification of seeds of bitter almond (local variety) which grow under rain fed (unirrigation) conditions in north of Iraq.This research was initiated with the following objectives :

a- study the effect of stratification periods on seed germination.

b- study the dynamic changes of ABA that occur during stratification in bitter almond seeds and endocarp and it's relation to seed germination .

\section{MATERIALS AND METHODS}

This experiment was conducted at the Plant Hormones Laboratory in the Department of Plant Production, Faculty of Agriculture, University of Jordan, Amman, Jordan, during the period 2004 to 2005 to study the content of endogenous free and bound abscisic acid (ABA) during five stratification periods and improve seed germination of Prunus amygdalus L. Mature bitter almond seeds Badam variety or Mosul no.338 according to (Townsend and Guest, 1966), local variety were collected from trees grown in Sulaimania orchards, north-east of Iraq which grow under rain full conditions (unirrigation). Endocarps with empty or dead seeds were separated from those with viable seeds by floating in a $20 \%$ solution of sodium chloride, and tested for viability using the triphenyl tetrazolium chloride procedure (Qrunfleh ,1991).

Cold Stratification and Seed Germination : The seeds with their endocarps were stratified for 0 (without stratification), 15, 30, 45 and 60 days at $5{ }^{\circ} \mathrm{C}$ using perforated polyethylene bags filled with moistened perlite. After each stratification period, the seeds were divided into two parts :

(1) the stratified endocarps were split apart and seeds (embryo with the storage tissues) were excised and both parts were freeze dried and kept at $-20{ }^{\circ} \mathrm{C}$ until used for abscisic acid (ABA) analysis and,

(2) the stratified endocarps were germinated on four plates filled with peatmoss and perlite 1 to $1(\mathrm{v} / \mathrm{v})$ at $24 \mathrm{C}^{\circ}$ according to Qrunfleh (1991). Each plate represented one replicate and contained five treatments (30 seeds each enclosed in its endocarps) in a completely randomized block design.

Abscisic Acid Analysis : Abscisic acid in the seeds and their endocarps was extracted using a modification procedure of Takeda and Crane (1980) and Gaith (1988). Fifty grams of the ground seeds from each treatment were homogenized in a $100 \mathrm{ml}$ of $80 \%$ methanol $(\mathrm{MeOH})$, at $5{ }^{\circ} \mathrm{C} \pm$ for 24 hours 
under continuous stirring by magnetic stirrer and filtered in a $15 \mathrm{~cm}$ diameter Ederol No. 11 filter paper. The residues in the filtered were washed two times (2x) with $100 \mathrm{ml}$ of $100 \% \mathrm{MeOH}$. The volume of the $80 \% \mathrm{MeOH}$ and $100 \%$ $\mathrm{MeOH}$ were bulked and then reduced to the aqueous phase in vacuo at $40{ }^{\circ} \mathrm{C}$, using a rotary evaporation (Rota vapor Rllo). The aqueous phase was increased to $20 \mathrm{ml}$ using distilled water, then it was adjusted to $\mathrm{pH} 8$ with $1 \mathrm{~N} \mathrm{NaOH}$, kept overnight to freeze. The frozen aqueous phase was then thawed next day and partitioned $3 \mathrm{x}$ with $10 \mathrm{ml}$ of petroleum ether (Pet.Et.) using a separatory funnel to remove weaker acids. The Pet.Et. was discarded and the aqueous phase was partitioned again $3 \mathrm{x}$ with $10 \mathrm{ml}$ of ethyl acetate (EtoAc.). The bulked EtoAc $(30 \mathrm{ml})$ was washed with $3 \mathrm{ml}$ distilled water and was discarded. The $3 \mathrm{ml}$ distilled water were bulked with the aqueous phase (20ml). The aqueous phase $(23 \mathrm{ml})$ was adjusted to $\mathrm{pH} 3$ with $1 \mathrm{~N} \mathrm{HCl}$ and partitioned $3 \mathrm{x}$ with $10 \mathrm{ml}$ of EtoAc. The aqueous phase was saved for bound ABA and the EtoAc for free ABA. The aqueous phase contained bound ABA was treated with 6 drops of $12 \mathrm{~N} \mathrm{HCl}$ for one hour at $60{ }^{\circ} \mathrm{C}$ to hydrolyze the conjugated ABA . The $\mathrm{pH}$ was adjusted to 3.0 by 6 drops of $12 \mathrm{~N} \mathrm{NaOH}$ and partitioned $3 \mathrm{x}$ with $10 \mathrm{ml}$ EtoAc. The following steps later on followed exactly those mentioned for free ABA analysis. The EtoAc phase containing free ABA was dried in a rotary evaporator. The dried residue was dissolved with $20 \mathrm{ml}$ phosphate buffer $\left(0.1 \mathrm{M} \mathrm{K}_{2} \mathrm{HPO}_{4}, \mathrm{pH} 8.0\right)$. The $20 \mathrm{ml}$ phosphate buffer were shaked for 15 minutes (min) with one gram of insoluble polyvinylpyrrolidone (PVP) using a magnatic stirrer to remove the phenolic compounds . The PVP was first prewashed with $\mathrm{MeOH}$ and acetone, then it was air dried. The compound containing PVP and phosphate buffer was centrifuged at $6000 \mathrm{~g}$ for 30 min. The supernatant was collected with a pipet and the PVP was discarded. The supernatant was adjusted to $\mathrm{pH} 3.0$ with $1 \mathrm{~N} \mathrm{HCl}$, partitioned $3 \mathrm{x}$ with 10 $\mathrm{ml}$ of EtoAc and then dried in vacuo at $40{ }^{\circ} \mathrm{C}$ using a rotary evaporator. The dried residue was dissolved in a $5 \mathrm{ml}$ acetone for further purification

Thin Layer Chromatography (TLC) : The acetone solution (5ml) was chromatographed along with a mixture of $( \pm)$ cis-trans ABA standard (Sigma) using silica gel GF $20 \times 20 \mathrm{~cm}$ plates (Fisher). The standard and the acetone solution were loaded separately on the plates as a narrow band. The plates were developed in benzene: EtoAc: acetic acid (HoAc) 75:20:5 V/V/V/ for one hour. Naturally occurring free and bound ABA in bitter almond seeds and endocarps were visualized on the GF plates by $\mu \mathrm{V}$ light at $254 \mathrm{~nm}$ at $\mathrm{rf} 0.43-0.48$. This method was used as a preliminary identification of ABA in better almond seeds. The corresponding zones on the plates were scraped off and immediately eluted with $10 \mathrm{ml}$ of acetone. The eluent was filtered with a PTFE (Millipore) pore size $0.5 \mu \mathrm{m}$. The filtrate was dried under $\mathrm{N}_{2}$ gas and the residue containing ABA was dissolved in $200 \mu \mathrm{l}$ of $\mathrm{MeOH}$ for high performance liquid chromatography (HPLC) .

High Performance Liquid Chromatography: Ten $\mu \mathrm{l}$ of the $200 \mu \mathrm{MeOH}$ containing free ABA were injected into the sample injection valve model 210. Free ABA in the $200 \mu \mathrm{l}$ sample from almond seeds and endocarps was 
identified depending on the retention time (1.3-1.7min) of known standard concentrations of ( \pm ) cis-trans ABA from Sigma (Fig .2).

Abscisic Acid Quantification : Naturally occurring ABA in seeds and endocarps of bitter almond was quantified using standards of a mixture of cistrans ABA from Sigma. The standard curve equation in Fig. (1), was established from the measured peaks and concentrations of ABA standard as follows :

$\mathrm{Y}=\mathrm{a}+\mathrm{bx}$. where $\mathrm{Y}$ is peak aera . $($ Peak area $=7158.6 \times+2353.1)$.

This equation represents the relationship between peak area and ABA concentration as shown in (Fig.2) was used for naturally occurring ABA quantification in bitter almond seeds and endocarps. As concentration of ABA to be expressed in $\mu \mathrm{g} / \mathrm{g} \mathrm{F}$. Wt, equation two $\left(\mathrm{q}_{2}\right)$ was used :

$\mathrm{q}_{2}=\mathrm{X} \mu \mathrm{g} / 100 \mu \mathrm{l} \times 200 \mu \mathrm{l} \times 1 / 50 \mathrm{~g}(\mathrm{wt}$. of sample).

(x) is the concentration of $\mathrm{ABA}$ in $\mu \mathrm{g} / 100 \mu \mathrm{l}$. and volumes of pure synthetic ABA (sigma), as shown in Figure (1).

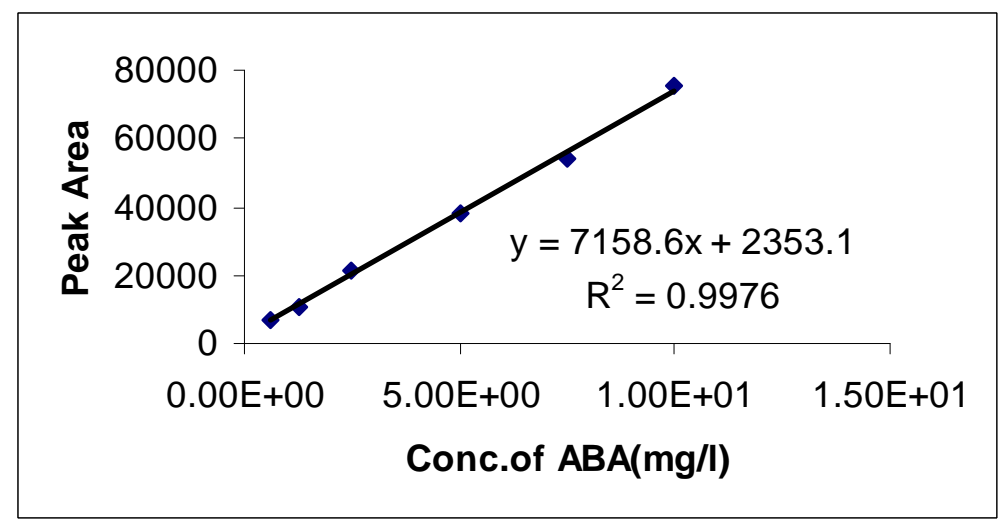

Fig.(1):Calibration curve of pure ABA.

Statically analysis was performed Complete Randomized Design with three replicates were used, and means were compared by Dancans Multiple Range Test at the $1 \%$ probability level ( SAS,2001).

\section{RESULTS AND DISCUSSION}

Effect of stratification periods on abscisic acid content in seeds and endocarp: Fig. 3 showed that there is a significant decline in the free and bound ABA content of seeds and endocarp of bitter almond Badam variety during the first 15 days but a sharp decline was occurred during the first 45 days. After that the decreasing in ABA content was happened on 60 days stratification period. The reduction in free ABA was sharper between the 45 and 60 days of stratification than from zero to 15 days. During the first 30 days of stratification there was a high significant lowering in bound $\mathrm{ABA}$ in the seeds. After the first 30 days, a gradual decline was occurred in bound ABA which was continued until the end of stratification process, but the high significant decreasing in bound $\mathrm{ABA}$ in the endocarps was registered during the first 15 days to the end of stratification. However, the number of days of stratification increased, the 
ABA level in the seeds while decreased in the endocarps. Germination percentage was significantly increased especially in 45 days (Fig.3).

Effect of stratification periods on germination percentage: Fig. 4 showed that the bitter almond seeds stratified for 60 and 45 days gave a significantly lower concentrations of total ABA in seed. The bitter almond seeds were stratified for 45 days led to a high significant percentage of germination $(85.133 \%)$ as compared with those treatments stratified for $0,15,30$ and 60 days, were gave $10.5 \%, 25.4 \%, 41.1 \%$ and $73.1 \%$, respectively. The stratification of bitter almond seeds at $5{ }^{\circ} \mathrm{C}$, was very effective for cracking the endocarp and that due to the imbibitions of water by the seeds which in turn caused an expansion of the embryo cells or tissues (Gaith,1988). The stratification for 45 days is needed to remove endocarp and embryo induced dormancy. The decrease of ABA content in endocarp during stratification periods showed that both free and bound $\mathrm{ABA}$ in the endocarp leached by the moisture stratification medium or into the embryo, where it was converted into bound $\mathrm{ABA}$, or by degratation of $\mathrm{ABA}$ to simpler compounds during stratification (Daiz and Martin, 1972; Toiet et. al., 1979; Giath, 1988).

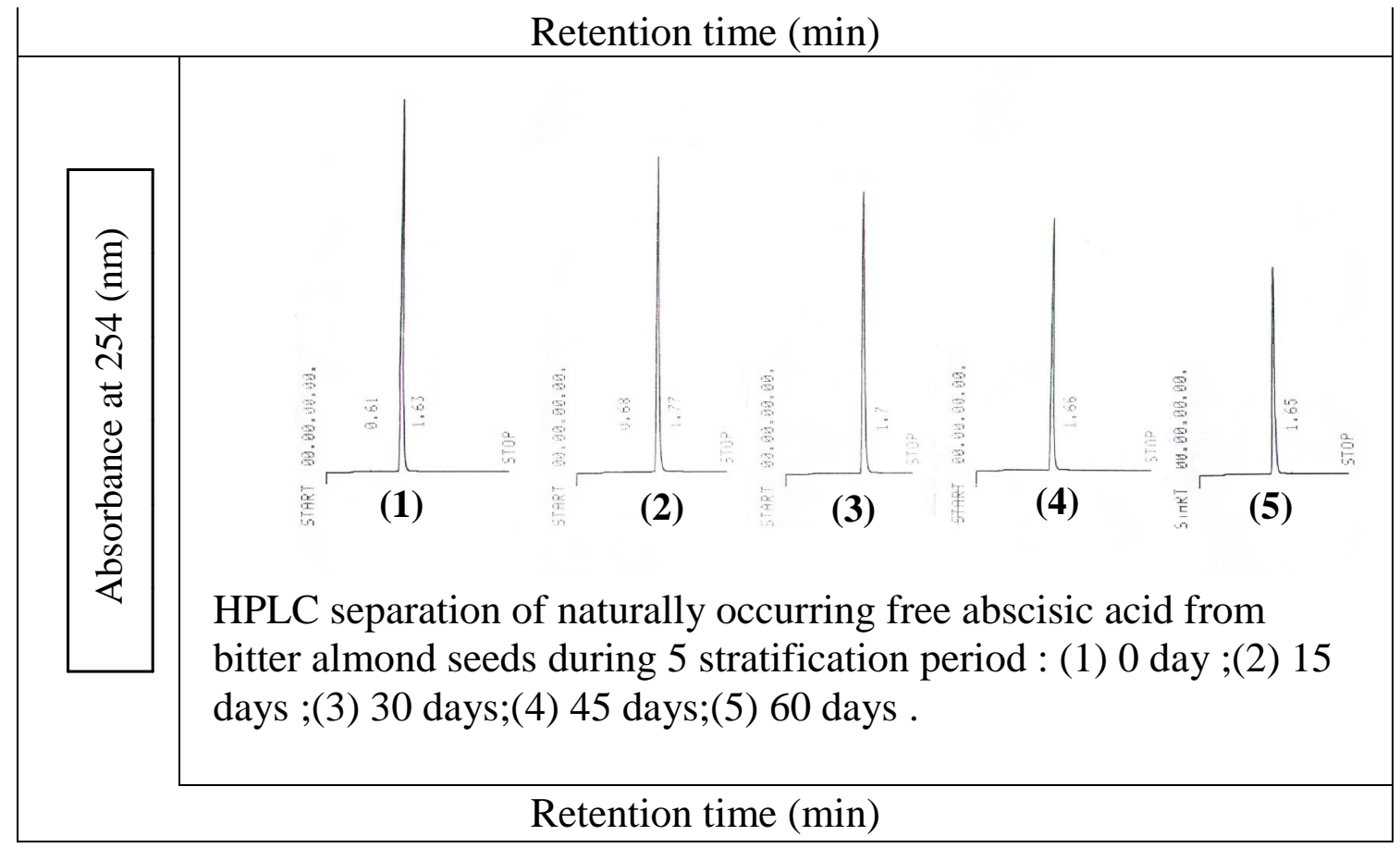




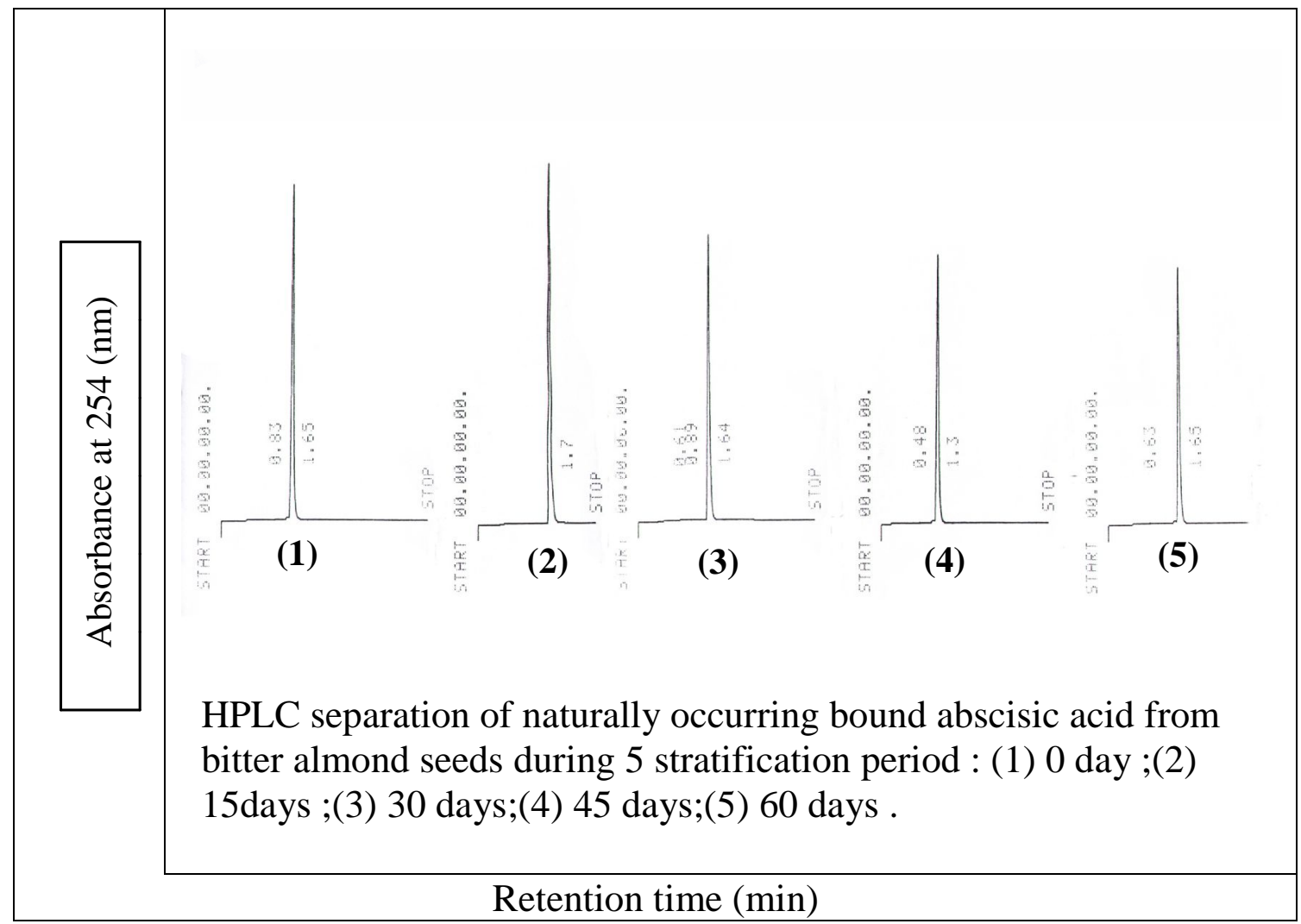

Fig. (2): HPLC separation of naturally occurring ABA on extract of bitter almond seeds.

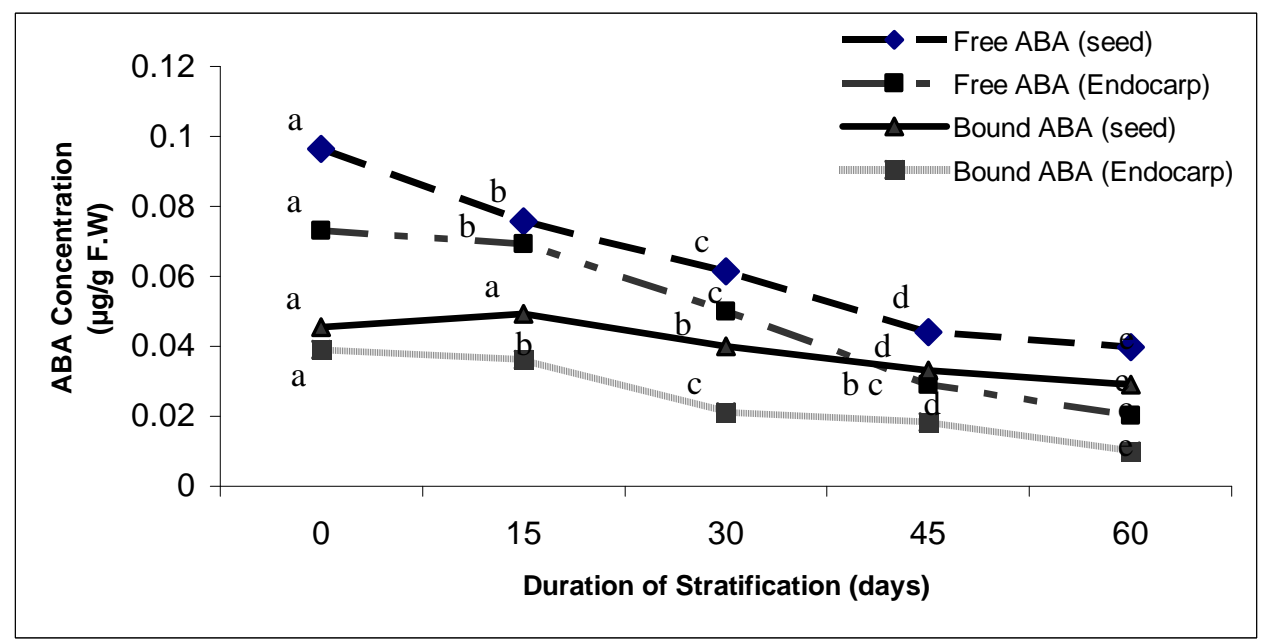

Fig. (3): Effect of stratification periods on free and bound ABA concentration in bitter almond seeds and endocarps. Each datum point represents an average of 3 injection in HPLC.

This extension might lead to a considerable increase in endogenous growth - promoting hormones or enzyme activity (Qurnfleh, 1991). We can conclude to the nurserymen in Iraq that the stratification of bitter almond seeds must be not more than 45 days for the germination seeds which will be 
damaged during prolonged stratification period and that was in agreement with Giath, (1988).

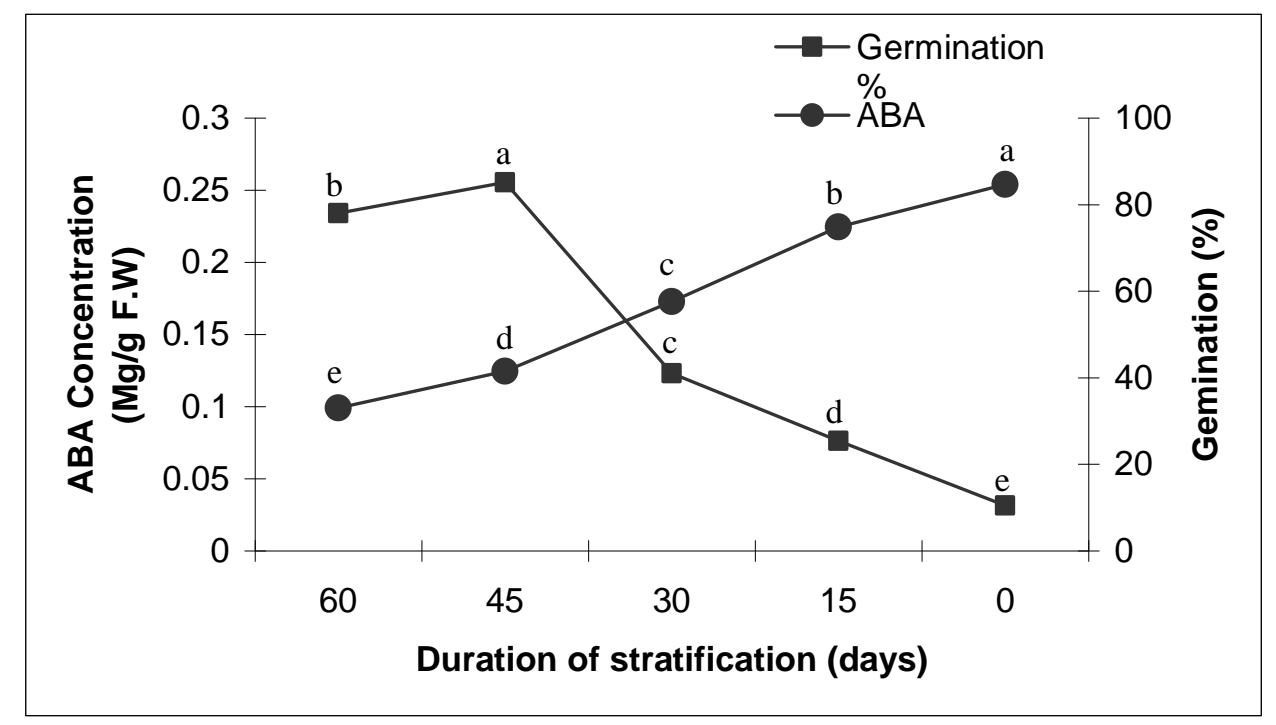

Fig. (4): Effect of stratification periods on germination percentage and ABA concentration in Bitter almond seeds and endocarps. Germination points followed by the same letter are not significantly different at $\mathrm{P}=0.05$, but total 


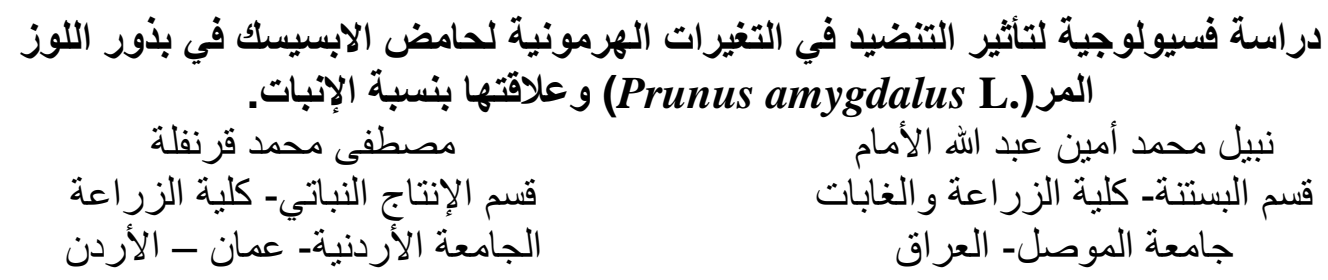

(الخلاصة

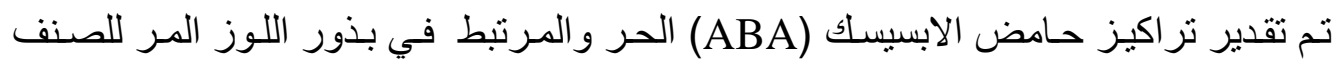

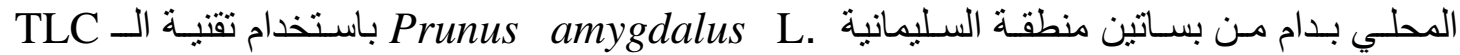

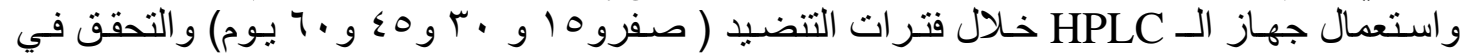

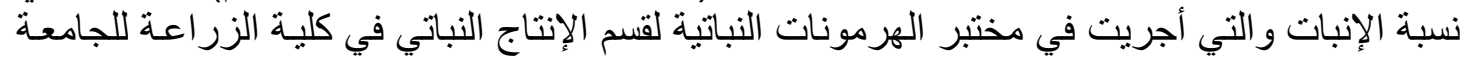

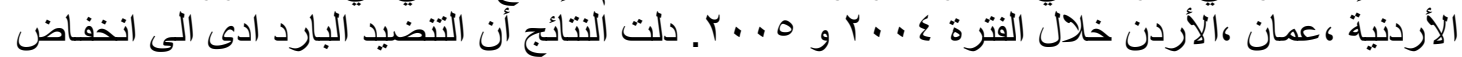

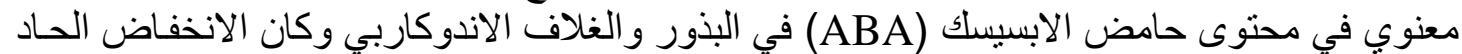

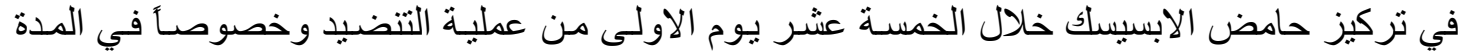

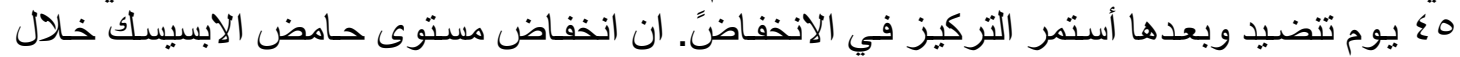

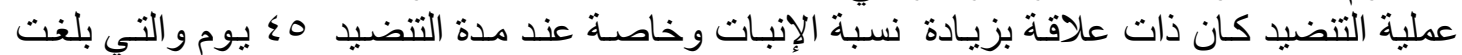

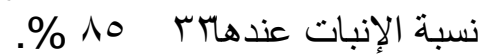

\section{CKNOWLEDGEMENT}

The investigators wish to express their sincere gratitude and appreciation to the College of Agriculture \& Forestry, University of Mosul, Iraq .Thanks to the Chief of the AHEAD Project, for awarding the opportunity to accomplish this work and their financial support. Thanks also due to the Technical Staff of Plant Hormones Laboratory at the Department of Plant Production, Faculty of Agriculture, University of Jordan, Amman, Jordan.

\section{REFERENCES}

Addicott, F. (1992). Abscission. Berkeley : Univ. of Calif. Press.

Bonamy, P.A. and F.G. Dennis JR (1977). Abscisic acid levels in seeds of peach. II. effects of stratification temperature. J. of the American Society for Horticulture Sci., 102: 26-8.

Daiz, D.H and G.C. Martin (1972). Peach seed dormancy in relation to endogenous inhibitors and applied growth substances. J. of the American Society for Horticulture Sci., 97: 651-4.

Gaith. M.H. (1988). Abscisic acid level in bitter almond seeds Prunus amygdalus L. as influenced by stratification. Thesis, University of Jordan, Amman, Jordan.

George, E.F. (1993). Plant propagation by tissue culture, part 1. The technology. Edington, Wilts, England : Exergetics, ltd.

Hartmann, H.T. and D.E. Kester (1975). Plant Propagation Principles and Practices. $3^{\text {rd }}$ ed. Printice. Hall Engle Wood Cliffs. N.J. USA.

Hartmann, H.T., D.E. Kester, F.T. Davies and Jr. R.L. Geneve (2002). Plant Propagation Princicples and Practices. $7^{\text {th }}$ edition Prentice Hall, Upper Saddle River, New Jersey 07458.

Hopkins, W. G. and N. P. A Hüner (2004). Introduction of Plant Physiology. 3rd Edition. John Wiely \& Sons, Inc. USA. 
Khalil, R.Y. (1997). Changes in abscisic acid level by cold stratification and influence of certain plant bioregulators and cold stratification on seed germination of amygdalus Arabica Oliv. M.Sc. Thesis of Faculty of Graduate Studies, University of Jordan, Amman, Jordan.

Qrunfleh, M.M. (1989). Free and bound abscisic acid in buds of Nabali olive (Olea europaea L.).Advances in Horticultural Sci., 3: 99-101.

Qrunfleh, M.M. (1991). studies on the hawthorn (Crataegus azarollus L.): II. Changes in abscisic acid content during cold stratification in relation to seed germination. J. of Horticultural Sci. , 66 (2) : 223-226.

Ponicelot, R.P. (2004) Sustainable Horticulture Today and Tomorrow, Prenice Hall, Upper Saddle River, New Jersey 07458.

SAS ( 2001 ) SAS Users-Guide . SAS Institute Inc. Cary NC. USA.

Takeda, F. And J.C. Crane (1980). Abscisic acid in pistachio as related to inflorescence bud abscission. J. American Society For Horticulture Sci. 105: 573-576.

Tao, K. and A.A. khan (1976). Changes in isoperoxidases during cold treatment of dormant pear embryo. Plant Physiology, 57: 1-4.

Toiet, H.D., G. Jacobs and D.K. Strydom (1979). Role of the various seed parts in peach seed dormancy and initial seedling growth. J. of American Society For Horticulture Sci., 104 (4) : 490-492.

Townsend, C.C. and E. Guest (1966). Flora of Iraq. Publication of Ministry of Agriculture, Republic of Iraq. Baghdad.

Yousif,Y.H.(1987). Tree Fruit Propagation. Directorate of book house of printing and publishing. Mosul Univ., Mosul-Iraq.(In Arabic) 